\title{
O CAVALO DE TODAS AS CORES DE JOÃO CABRAL E ALBERTO DE SERPA: UMA REVISTA TRIMESTRAL DE UM NÚMERO SÓ \\ O CAVALO DE TODAS AS CORES BY JOÃO CABRAL AND ALBERTO DE SERPA: A ONE VOLUME TRIMESTRAL MAGAZINE
}

\author{
Priscila Oliveira Monteiro Moreira* \\ Manaíra Aires Athayde**
}

Resumo: No final dos anos 1940, João Cabral de Melo Neto correspondeu-se com o português Alberto de Serpa para propor a criação de um periódico a ser editado em sua tipografia artesanal, O Livro Inconsútil. A leitura da correspondência passiva depositada nos Arquivos Pessoais de Escritores Brasileiros, na Fundação Rui Barbosa, permitiu recompor o esforço dos poetas na organização da revista literária $O$ Cavalo de Todas as Cores. Essa experiência editorial de João Cabral é parte significativa de sua produção, além de ser um espaço de resistência política à censura portuguesa, de afirmação da cultura catalã e de apresentação da poesia de língua portuguesa a públicos estrangeiros. Palavras-chave: João Cabral de Melo Neto, Alberto de Serpa, censura literária, literatura e resistência

\begin{abstract}
In the late 1940s, João Cabral de Melo Neto corresponded with the Portuguese writer Alberto de Serpa about designing a magazine to be published by Cabral's in his letterpress named Livro Inconsútil [The Unbound Book]. The reading of the letters sent by Serpa to Cabral, which are stored at the Brazilian Writers Personal Archives at the Rui Barbosa Foundation, allowed me to rebuild the poet's efforts in editing, publishing and distributing the literary magazine $O$ Cavalo de Todas as Cores [The Colorful Horse]. This editorial experience is a significant part of João Cabral's production, representing a space for political resistance against Portuguese censorship, the affirmation of Catalan culture, and also the introduction of Portuguese poetry to a foreign audience.
\end{abstract}

Keywords: João Cabral de Melo Neto, Alberto de Serpa, literary censorship, literature and resistance

\footnotetext{
*Doutoranda em Estudos Avançados em Materialidades de Literatura pela Universidade de Coimbra (Portugal).

** Pesquisadora no Centro de Literatura Portuguesa (CLP) da Universidade de Coimbra (Portugal).
} 
m 1949, Alberto de Serpa Esteves de Oliveira agradece a João Cabral de Melo Neto pelos "três encantadores volumes que quis ter a amabilidade de enviar-me" (SERPA, 19 jun. 1949). Serpa referia-se a exemplares impressos em O Livro Inconsútil, editora artesanal que João Cabral manteve durante sua primeira temporada em Barcelona. Este foi o primeiro registro do que, durante dois anos, viria a ser uma volumosa troca de cartas, continuando de modo esparso nos anos seguintes. $\mathrm{O}$ acervo epistolar passivo de Melo Neto está depositado nos Arquivos Pessoais de Escritores Brasileiros, na Fundação Rui Barbosa, no Rio de Janeiro, para consulta local. O envio ativo do autor, todavia, foi adquirido pela coleção de manuscritos reunidos pelo poeta Alberto de Serpa, disponível na Biblioteca Municipal do Porto, em Portugal, sendo-nos fornecido apenas o resumo do conteúdo neste primeiro momento. ${ }^{1}$ Este artigo, portanto, procura reconstruir o diálogo epistolar desses dois poetas a partir do acesso aos textos completos de Serpa e de fragmentos de Cabral, com o intuito de identificar a relevância da editora O Livro Inconsútil para o cenário político e literário da época.

As cartas entre 1949 e 1951 revelam um plano de trabalho comum: o projeto de lançar uma revista literária. Inicialmente voltada para a poesia, 0 Cavalo de Todas as Cores teria tiragem trimestral, contaria com portugueses, brasileiros e catalães, e seguiria as características físicas das demais obras da editora (numerada, de formato pequeno, impressa em fonte Bodoni e com duas cores apenas). Arremata o português não ter "possibilidades de concorrer com dinheiro para essa empresa", mas que venderia com facilidade 50 exemplares, "e gostaria de saber o que o João pensa fazer quando da [sic] expansão aqui e no Brasil". Os critérios para seleção editorial eram claros: escolher poetas próximos, renomados ou que estivessem enfrentando dificuldades para publicar em seus países de origem. O periódico seria um espaço de combate à censura salazarista, franquista e pós-Estado Novo, buscando manter a língua materna de cada colaborador como forma de afirmação e resistência. Impossibilitados de lançarem seus textos, os autores seriam contatados por Cabral ou Serpa, que imprimiriam por conta própria na gráfica caseira montada pelo brasileiro em 1947.

\footnotetext{
${ }^{1}$ Todas as referências epistolares feitas entre João Cabral de Melo Neto e Alberto de Serpa são reveladas por este ensaio de forma inédita, sendo esta a primeira vez, então, que são publicadas. Os desdobramentos desta pesquisa serão aprofundados na tese que está em período de escrita, dedicada à produção editorial do poeta pernambucano.
} 
No final dos anos 1940, Alberto de Serpa havia participado da última fase da revista Presença (de 1927 a 1940, em Coimbra), sendo secretário em suas duas últimas tiragens. Esse movimento possui importância inquestionável não somente para a literatura portuguesa, mas também pela divulgação de brasileiros que passam a publicar por lá. Em seu acervo, Alberto de Serpa guarda missivas de amigos de longa data, como Manuel Bandeira e Cecília Meireles, mas também incluindo correspondentes eventuais como Carlos Drummond de Andrade, Augusto Schmidt e Mario de Andrade. Alberto de Serpa trata-se, portanto, de um articulador cultural disposto a dialogar com seus contemporâneos, emitindo relatos elogiosos a Jorge Amado e a Jorge de Lima, de quem era leitor. A motivação de divulgar a cena modernista brasileira continuou na Revista de Portugal (1937 a 1940 em Coimbra), Cadernos de Poesia (1940 a 1942) e continuou posteriormente em Távola Redonda (1950 a 1954 em Lisboa), mantendo o entusiasmo com a produção nacional.

Na resposta ao primeiro contato, Alberto de Serpa oferece originais que poderiam interessar ao poeta e impressor, aceitando o convite:

Tenho verdadeiro prazer em estreitar relações com esse poeta que muito admiro pelos seus versos e, agora, pela maravilhosa obra que está a fazer a bem da poesia [refere-se aos livros artesanais]. Não deixe de mandar-me algumas de suas belas edições, mesmo em folhas de ensaio. Dou sim imenso valor a essas coisas e guardálas-ei aqui com avareza e amor. [...]

Se minha colaboração lhe interessa, a mim honrar-me-á. (SERPA, 19 jun. 1949)

Mantendo o costume editorial de encaminhar obras para influentes formadores de opinião, João Cabral encaminha os impressos d’O Livro Inconsútil a Serpa. A intenção de organizar uma revista, todavia, já existia há meses, mas faltavam-lhe ainda as articulações necessárias. Ao perceber a abertura de Alberto de Serpa para publicar, fez-lhe uma proposta. Na carta seguinte, o português responde e sugere um título:

Para os seus livros sem costura que me encantarem, terá você sempre o meu maior entusiasmo, e será só pedir, não por boca, mas por papel - infelizmente - tudo o quanto quiser. Não haverá demora para qualquer desejo seu, tenha a certeza. 
Quanto a essa ideia da nossa Revista, estou já possesso dela. Já a vejo na minha frente, e já Ihe sugiro um título - $O$ Cavalo de Muitas Cores. Sob, ou sobre as letras, um Pégaso formoso, que o Almada Negreiros ou Cícero Dias desenharão da melhor vontade, e a que a sua Tipografia dará uma cor em cada número. Que lhe parece? Acho muito bem os 4 cadernos de 8 páginas trimestrais, e a colaboração portuguesa não faltará. Dado o pequeno comprimento, sugiro, por agora, as colaborações apenas brasileira e portuguesa: uma revista de boa poesia e boa apresentação de cá e de lá, já é alguma coisa. Quatro colaboradores por número, dois portugueses, dois brasileiros, sendo três poetas e um prosador. $\mathrm{O}$ primeiro número deverá dar já dos melhores, e, assim, lembro-me do nosso Bandeira, ou do Drummond, e de qualquer outro seu patrício; de cá, prosa poética do Régio ou do Gaspar Simões e versinhos do Miguel Torga. Para o $n^{\circ} 2$, já tenho inéditos do Nobre para um caderno e, para lá mais para diante, faremos um nº́ só com uma longa e admirável poesia inédita do Fernando Pessoa. Que me diz? (SERPA, 17 jul. 1949 , grifos nossos)

Cícero Dias foi mencionado na carta como provável desenhista da capa. "Pintor do Capibaribe", como o chamaria na dedicatória do Cão sem plumas, fazia parte do perfil de colaboradores de João Cabral que abarcava o escopo da editora, e Alberto de Serpa sabia disso. A prioridade também residia em ter seu estado de Pernambuco representado, como já o tivera ao publicar Manuel Bandeira e Joaquim Cardoso em 1948, com Mafuá do malungo: jogos onomásticos e outros versos de circunstância e Pequena antologia pernambucana, respectivamente. Almada Negreiros, por sua vez, seria contato direto de Serpa, por conta da amizade que nutriam desde a Orpheu e a Presença. A editora O Livro Inconsútil atuou de 1947 a 1953, publicando autores pouco conhecidos ou marginalizados pela censura, como os catalães Joan Brossa, Juan Ruiz Calonja, Juan Eduardo Cirlot; um dos principais objetivos de João Cabral era registrar a língua catalã, banida na Espanha durante a ditadura de Francisco Franco. O Cavalo de Todas as Cores insere-se neste contexto. O primeiro e único número da revista criou a expectativa de ser mais do que um periódico, transformando-se também em um reduto de resistência da liberdade artística contra a repressão local. Joan Brossa sempre reforçou a importância e o respeito intelectual por João Cabral, "com quem conviveu na Espanha franquista do segundo pós-guerra (a casa do 
poeta e vice-cônsul brasileiro funcionando como um território livre, onde se podia discutir arte contemporânea e política)" (BROSSA, 2005, p. 53).

Para Serpa era fundamental que a revista tratasse apenas sobre poesia para ser um espaço de afirmação da poesia, que por si é um gênero cujo público-leitor é reduzido:

Acho que maior interesse teria a publicação, em O Cavalo, de pequenos estudos sobre poesia e poetas, estudos que os autores raramente retornam para livro, e de poesias nas gavetas dos nossos confrades, embora estas venham a sofrer o risco de caírem. Toda a poesia esteve sempre neste risco, e as Revistas não deixaram de ter sempre o maior interesse. (SERPA, 4 set. 1949)

Há um destaque no final da segunda carta de Serpa: "PS: Será bom o meu Amigo ver com atenção, aí, a subordinação da Revista aos serviços da Censura. Vou ver o caso aqui, também, de forma a não termos qualquer impedimento futuro" (SERPA, 17 jul. 1949, grifos nossos). Legado à posição de post scriptum, o assunto, no entanto, não era pouco relevante. No envio seguinte, explicaria melhor o receio:

Não, não houve qualquer regresso, no meu sonho do nosso $O$ Cavalo de Todas as Cores, que já vejo a correr por aí fora - terras, mares, ares - com as suas asas poderosas. A ideia da Revista traz-me possesso, e já pude arranjar o entusiasmo de todos os meus amigos que serão os nossos ajudantes. Posso, logo que você me responda a esta carta, mandar-lhe a colaboração portuguesa.

Tenho que explicar-Ihe o seguinte: no ano passado, fui encarregado, pelo Director do Janeiro, um capitalista que não se importava com perder alguns centos de contos de reis por ano, de dirigir uma grande Revista Literária e artística. [...] 0 Director da Propaganda... e da Censura negou-me essa autorização: ser-me-ia dada, se eu entrasse em um acordo com ele. [...] Assim, coagido a sujeitar-me à Censura, para a publicação da Revista, desisti de lançá-la, e aproveitei o último período de liberdade condicionada para atacar o [António] Ferro numa entrevista que aqui deu grande brado. Por essas razões, não posso lançar em Portugal uma

Revista, sem autorização da Censura. Penso que nada me proíbe, nada sofrerei, nada sofrerá uma Revista lançada em Espanha, e preocupada, apenas, em dar boa poesia - de todas as cores. Não sei, no entanto, se para a possível sua vinda, num 
dia, para Portugal, em exercício da sua carreira, terá influência a sua ligação comigo. Sinceramente, meu caro João Cabral, ponho-Ihe este caso, para você ponderar e sobre ele resolver. [...]

Sou um homem sem qualquer ligação política, um democrata independente que combate, só pelas suas palavras, qualquer extremismo da direita, ou da esquerda. Esta explicação legal também lhe dou, para você saber com quem se mete. (SERPA, 4 set. 1949, grifos nossos)

A briga com Estado Novo já levava anos. Sendo alvo de António Ferro, um dos políticos de confiança de Salazar, seria difícil para Serpa fugir do regime em um país cuja extensão territorial é pequena quando comparada à Espanha ou ao Brasil. Para alertar João Cabral sobre problemas e tranquilizá-lo, as afirmações do português foram retificadas contraditoriamente diversas vezes: assim como inicialmente desconfiava de algum prejuízo à carreira diplomática do brasileiro, a seguir afirmava que esse aspecto político não haveria de prejudicar em suas colocações futuras.

Outros trâmites precisavam estar bem ajustados para que não houvesse risco, como a ortografia da língua portuguesa e o país vinculado à publicação: era preciso estar expresso que a revista era espanhola, só assim a publicação não seria taxada com o imposto nacional ou se enquadraria como contrária aos fins do regime político vigente.

Se Ihe falei no caso do seu endereço foi prevendo dificuldades que aqui me levantassem e a probabilidade de alguém querer dirigir-se à Revista ou aos organizadores. A primeira hipótese fica vencida desde que figure em qualquer ponto do Cavalo a indicação de que é você o impressor [...]

Um aviso importante: retire os acentos circunflexos do título do Cavalo. Com eles sobre todas e cores, a revista não poderia circular em Portugal!!! É espantoso, mas cá, a não aceitação da ortografia do famoso acordo leva à apreensão dos trabalhos... tempos tristes...

O António Ferro, que já sabe do nosso projecto, está "muito sentido" comigo por eu não me ter sujeitado à sua imposição de ir à Censura... Bem calculo que visto lhe custe, por se saber no Brasil que eu não posso publicar livremente uma Revista de Literatura e Arte em Portugal. (SERPA, 6 out. 1949, grifos sublinhados do original) 
Deixe-me fazer-lhe dois pedidos que considero importantes: $1^{\circ}$ - dar, na capa, a indicação de que $\boldsymbol{O}$ Cavalo é composto e impresso em Barcelona, no seu atelier, pois essa indicação, e só ela, isentará a Revista de ir à Censura portuguesa e me colocará fora de qualquer sanção. Além disso, será bom o leitor saber a quem poderá se dirigir para qualquer efeito; $2^{\circ}$ - quando tiver os exemplares prontos, faça-me a remessa deles em pacotes de peso de menos de 1 quilograma e em dias espaçados, pois em caso contrário a Alfândega demorará e terei que pagar direitos. Não esquece estes pedidos? (SERPA, 8 dez. 1949, grifos nossos)

Acertado os detalhes, era preciso definir o perfil da revista e os critérios de seleção dos textos. Sugere Alberto de Serpa que

O Cavalo deverá, parece-me, olhar só à altura literária da sua colaboração, indo buscá-la a todos os sectores onde haja bons poetas e bons críticos. [...] Argumento também de ponderar é este: pela sua limitada tiragem e pelas pessoas a quem vamos oferecer, a nossa Revista será uma obra de elite e não uma de divulgação. Os seus leitores, ao darem com uma antologia de Poeta seu conhecido, teriam o direito de, pensando como nós a respeito da crítica e do gosto pessoal, achar que... não valia a pena. (SERPA, 4 set. 1949, grifos do original)

Insiste o português em pagar sua parte vendendo exemplares, e questiona quantos seria possível oferecer em Portugal. O conceito sobre o periódico, no entanto, mostra-se como sendo um ponto de divergência: Serpa pressiona para saber sobre a distribuição no Brasil, sempre pensando na ampliação de uma revista que sequer havia sido finalizada; por fim, impacienta-se com a longa espera dos bonecos de impressão e desanima. Insistindo em recomendar indicações de autores para as edições seguintes, parece não perceber que suas exigências eram direcionadas a um impressor e tipógrafo que, nas horas não ocupadas pela diplomacia ou pela poesia, trabalhava neste projeto.

Como esta [maquette do Cavalo] ainda não chegou, suponho extravio, e, assim, aqui me tem a dar-lhe conta da dúvida e a responder-lhe.

Estou perfeitamente possesso do Cavalo, e muito gostaria de o ver sair em Outubro. Vou já anuncia-lo nos Suplementos Literários dos jornais de Lisboa e Porto, sem 
compromisso, claro!, de saída - falarei vagamente, na próxima época literária. Na pobreza de Revistas que vai por cá, nascerá uma grande curiosidade. [...]

E no Brasil, quanto à expansão? Por que não pensa em entregar a uma livraria séria a distribuição dos exemplares para venda e assinatura, e a um amigo firme a distribuição dos exemplares oferecidos?

Como vê, estou pensando ativamente no Cavalo. E já penso em números a vir. Que acha de um $\mathrm{n}^{\circ}$, em 1950, (cinquentenário do falecimento de António Nobre), de homenagem a este? - Um estudo, 8 páginas de poesias inéditas, 8 páginas de cartas inéditas, não menos importantes que os seus mais belos poemas. (SERPA, 20 set. 1949 , grifos nossos)

Após receber as provas iniciais da revista, Serpa passa a chamá-la carinhosamente de "Bicho". Até então, escritores catalães não haviam sido mencionados. "A maquette agrada-me sob todos os pontos: papel é excelente e a mancha fica equilibradíssima. Já o olho para estes papeis como se a coisa estivesse pronta e toda a meu gosto. Vamos a essa 'Bomba Atómica' do Vinicius, e vamos a esses catalães esquecidos!" (SERPA, 6 out. 1949). A lista definitiva de autores do número revela o interesse dos editores de equilibrar nacionalidades: dois portugueses, um brasileiro, dois catalães. Todos se associam diretamente às relações literárias dos editores. Homem de Mello e José Régio são expoentes daquela geração, sendo este último principal missivista de Serpa ao longo de toda a vida. Régio foi o primeiro dos autores indicados para publicar n'O Cavalo. Convém explicar que todos esses autores são perseguidos pelos respectivos regimes ditatoriais de cada país em questão.

Vinicius de Moraes havia sido notificado por carta sobre o andamento de $O$ Cavalo: "Estou agora imprimindo a revista: um poema do português $P$. Homem de Melo, sua 'Bomba atômica', umas coisas catalãs e umas de [Rafael] Alberti, ${ }^{2}$ não mandadas por ele, mas escolhidas aqui" (MELO NETO, out. 1949, in MORAES, 2003, p. 163). João Cabral explica que o andamento era lento por conta da revisão que fazia das provas do ensaio sobre Joan Miró e também por motivos de saúde (em breve, teria que fazer uma trepanação craniana). Vinicius diz a

\footnotetext{
${ }^{2}$ Apesar do plano inicial do texto de Alberti, não chegou a ser publicado, assim como a "Antologia castelhana" que não foi publicada, cuja identificação da autoria ficou inviabilizada, e Adolfo Casais Monteiro, que apesar de estar na lista dos próximos livros inconsúteis, não concluiu o trabalho até a extinção da editora.
} 
Manuel Bandeira que esta seria a primeira impressão do seu poema (MORAES, [7 maio 1950] 2003). A escolha editorial, portanto, ao longo desse processo de triagem, sugere-nos que um dos critérios fundamentais baseava-se em resistência política, dando especial destaque à temática do poema escolhido: os ataques nucleares à Hiroshima e Nagasaki. Em março de 1950, Vinicius seria acusado de ter aderido ao comunismo, razão pela qual retornou ao Brasil, conforme explica em carta a Rubem Braga (MORAES, [23 mar. 1950] 2003, p. 174). Com isso, o Itamaraty iniciaria sua fase de "caça aos diplomatas" suspeitos de serem comunistas, o que aconteceria meses depois com João Cabral.

Manter uma publicação por trimestre era o objetivo inicial. Depois dele, veio uma proposta de fazer uma espécie de fascículos (chamados pelos poetas de pliego), mas que acabou também por não acontecer. João Cabral continuava a aumentar o nível de dificuldade na composição gráfica da revista, inserindo nela artes plásticas e novos textos. Havia um claro conflito conceitual contrastando a experimentação de Cabral e a pressa de Serpa: "Os livreiros, aqui, abriram já assinaturas, e pedem Cavalos como nos restaurantes se pedem beefs... Quero ver se posso pôr a venda os 50 [exemplares]. Vou hoje fazer a lista das ofertas para os futuros colaboradores e os amigos de ontem, de hoje e de manhã" (SERPA, 13 nov. 1949).

Acho excelente a ideia de darmos em cada número um pliego dedicado às artes plásticas, mas qual a sua ideia completa? Um plástico em cada número, formando o caderno? Parece-me difícil, pois iríamos cair - dando o pliego em todos os números - numa Revista "de Poesia e Artes Plásticas". Sugeria, antes, que, de vez em quando, déssemos esse pliego como poesia, escolhendo só desenhos ligados à poesia por seu mais profundo sentido. [...]

Desistimos, então, do número de Outono, e vamos para o $n^{\circ}$ de Inverno! Oxalá você venha forçar e possa terminar o ${ }^{\circ} 1$ rapidamente. Aqui, há grande curiosidade pelo Cavalo.

Dê-me suas notícias rápidas - sim? (SERPA, 10 nov. 1949)

As sugestões para melhorias não param e a revista já começava a ser encomendada. $[\ldots]$

Os versos [de Vinicius] são bons e o aspecto gráfico mantém a altura da grande oficina de Barcelona! [...] Os pedidos de assinaturas vão surgindo nas Livrarias. E 
parece-me bem satisfazermos essa gente que, nos dias de hoje, quer ainda saber da Poesia... (SERPA, 21 nov. 1949)

Em novembro de 1949, João Cabral foi submetido a uma cirurgia no crânio; um mês depois foi novamente operado e, em julho do ano seguinte, ainda uma terceira vez. Durante sua primeira recuperação, enquanto esperava pela versão final do texto de José Régio, Cabral editou Vinicius de Moraes, com Pátria minha, e Joan Brossa, Sonets de caruixa, então a primeira publicação daquele artista plástico. Enquanto editava a revista, João Cabral também escrevia Cão sem plumas.

Que maravilhosas coisas você está fazendo! Toda a gente a quem mostro os primores da sua oficina fica embasbacada... [...]

Agradeço-Ihe a generosidade dos exemplares que quer destinar-me. Os 100 devem chegar-me para a venda e irão 40 (compreendendo os assinantes) e os restantes serão para ofertas aos colaboradores e amigos mais íntimos. O que se apure de vendas será para despesas de correio e ajuda da sua oficina (SERPA, 1 dez. 1949)

Em dezembro de 1949, Alberto de Serpa, junto com os votos de que o amigo tenha se recuperado bem, informa ter recebido as novas provas enviadas e já estar munido dos originais para a segunda edição.

Aí lhe mando os inéditos do Fernando Pessoa para o n 2. [...] Todos me perguntam quando sai $O$ Cavalo. Já tenho recebido alguns pedidos de assinaturas. Sempre resolvi entregar 40 exemplares à Livraria Portugália, que fará toda a distribuição por Livrarias principais e assinantes. (SERPA, 8 dez. 1949)

O modo de distribuição da revista era muito mais profissional do que o esquema a que João Cabral estava acostumado quando da distribuição dos livros que editava, então encaminhados para um amigo que ficava responsável por enviá-los por Correio aos destinatários escolhidos. Este era, pois, um sistema paralelo às formas de circulação tradicionais de impressos, característica das editoras artesanais e clandestinas. $O$ Cavalo, por sua vez, tinha assinantes, um preço de custo, livrarias envolvidas na distribuição. 
Neste imbricado processo, João Cabral é levado novamente a interromper a produção da revista devido a sua saúde:

Eu, O Cavalo, a Poesia, o Brasil - todos precisamos da sua saúde, das suas forças, para irmos por aí fora! Não demore essas notícias...

Acho excelente a sua ideia de incluirmos já no $1^{\circ}$ número esses misteriosos bonecos gravados, que já tanto me tinham interessado nos livrinhos; darão ao Cavalo uma certa variedade agradável. Nada de hesitações, pois, e vamos o animal, que são horas! [...] As suas propostas para o $\mathrm{n}^{\circ} 2$ - Bumba-meu-boi e ensaio de [Carles] Riba - ótimas! (SERPA, 18 dez. 1949)

Tradicionalmente, capas possuem nomes dos autores e o título da obra. Para um tipógrafo amador, manter uma portada com as informações clássicas e não modificar a sequência de um livro é mais seguro. Por ser uma revista, uma imagem na capa pode torná-la esteticamente mais atrativa, somando-se a isso o insistente pedido de Serpa: "Por favor, não esqueça a indicação, na capa, da impressão e redação em Espanha (essencial para minha segurança)" (SERPA, Porto, 28 dez. 1949, grifos do original). A solução encontrada por Cabral tornou a forma da revista um tanto híbrida: possuía formato de livro $(14,5 \times 21,5)$, características de livro, mas o título de revista. Para manter a imagem do cavalo, foi preciso usá-la como uma espécie de sobrecapa, mas sendo, na verdade, a capa em si. Para inserir os dados que Serpa exigia sem danificar a estética do livro, colocou-os na folha de guarda, no verso da capa. Para que houvesse a lista de autores e obras que não "sujasse" a folha de rosto com um sumário, já que abria a edição diretamente com um poema identificando seu autor, criou uma espécie de lista na contracapa com o conteúdo a ser encontrado em sequência. O desenho da capa ficou a cargo de Francesc García Vilella, ilustrador de Cores, perfumes e sons, poemas de Charles Baudelaire traduzidos por Osório Dutra, lançado pel'O Livro Inconsútil no ano anterior. Vilella, artista catalão surrealista, pertencia ao grupo Dau au set. 


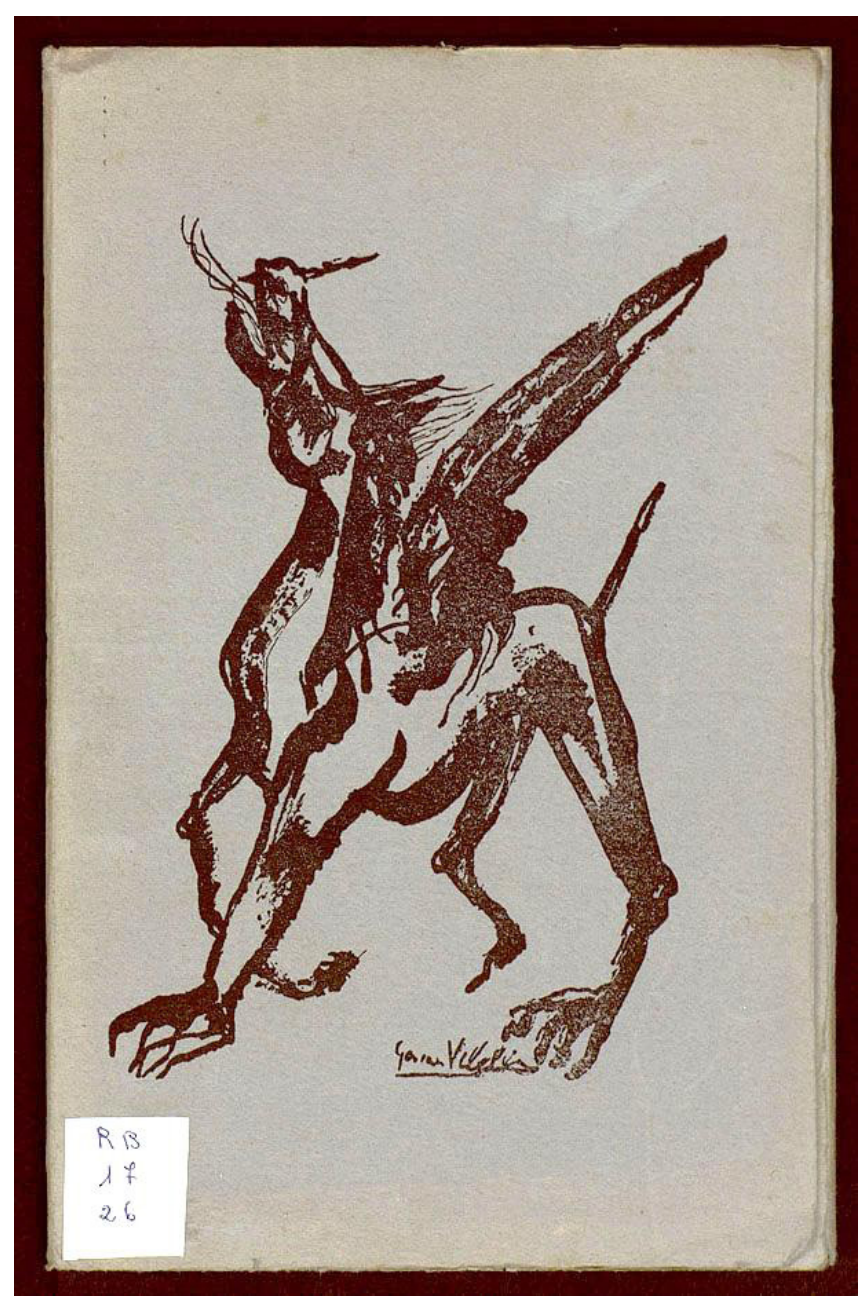

Figura 1: Capa de O Cavalo de Todas as Cores, ilustrada por Garcia Vilella. Exemplar da Biblioteca Geral da Universidade de Coimbra. 
O CAVALO DE TODAS AS CORES \& revista trimestral dirigida por ALBERTO DE SERPA C JOÁO CABRAL DE MELO NETO $\&$ tiragem limitada a duzentos exemplares $\S$ publicada em Barcelona por João Cabral de Melo.

Figura 2: Detalhe da folha de guarda no verso da capa.

Sumário do número 1 , de janeiro de 1950: PEDRO HOMEM DE MELLO, Nove canções católicas § vinicrus DE MORAES, A bomba atômica $\S$ R. SANTOS TORROELLA, Cuatro poetas $\S$ JOSÊ RÉGIO, Poesia $\&$ E. TORMO, Xilografía popular en Cataluña

Figura 3: Detalhe da lista de autores e obras na contracapa.

A partir de janeiro de 1949, as cartas de João Cabral passam a ser mais espaçadas. Isso leva Serpa a reflexão de retirar da capa a indicação da frequência trimestral dos números.

Publicados no Cavalo [os poemas de Pessoa], chamarão para ele inúmeras curiosidades - o meu querido Fernando [Pessoa] é hoje uma doença dos literatos e dos bibliófilos portugueses. Lá para o $10^{\circ}$ número, se você concordar, daremos um inédito dele, um poema longuíssimo que é uma obra fundamental da poesia portuguesa e de que eu sou o detentor.

Tenho, para números futuros, coisas berrantes, como p.e., as poesias pornográficas do João Penha, inteiramente inéditas e desconhecidas, autênticas maravilhas do gênero (retiraremos, é claro, o caderno, dos exemplares enviados a senhoras...) 
[...] Logo que tenha um exemplar concluído, mande-mo - sim? Estou como um mocinho à espera do brinquedo do Pai Natal (SERPA, 28 dez. 1949)

Acho prudente não se fixar prazo para a saída dos números do Cavalo, pois, fixado ele e chegado, de todos os lados começarão a perguntar-me as razões da demora, e eu ver-me-ei aflito para explicá-la. Por aqui, já com ironia se levantam perguntas... Assim, será melhor retirar da capa, se ainda não está impressa, qualquer referência à estação, a mês - não lhe parece? [...] Assim, lá mais longe [na Inglaterra], que vai ser do Cavalo? (SERPA, 26 fev. 1950, grifos nossos)

Ter esperado o lançamento desde outubro fez com que Alberto de Serpa recebesse a revista em março com renovado entusiasmo:

Sim, senhor: já cá chegaram dois pacotes com Cavalos. E foi para mim uma grande alegria folhear a nossa bela Revista. Agradeço-lhe muito todas as maçadas que teve com esse empreendimento para que eu, afinal, nada dou. A quem tenho mostrado, fica de boca aberta, pois aqui não se está habituado a tanto luxo e a tão bom gosto. Parabéns ao notável impressor! [...]

E vamos começar já com o $n^{\circ} 2$, para ganharmos a regularidade em Abril? [...] Não hesite, e atire-se já ao $n^{\circ} 2$, Amigo!

Vou pôr à venda 35 exemplares em livrarias de Lisboa, Porto e Coimbra, para que quaisquer poucos interessados tenham possibilidade de adquirir. [...] Suspiro, agora, por todos os 80 Cavalos, para fazer a distribuição. Não me largam com perguntas. (SERPA, 5 mar. 1950)

Ainda tenho cá apenas 40 Cavalos. [...]

Já tenho mostrado o nosso bichinho a alguns mais íntimos amigos, e todos se mostram encantados. Temos coisa, Seu João.

A minha parte do $n^{\circ} 2$ já está resolvido: Pessoa, Leonor de Almeida e Almada Negreiros com poemas em francês e uma ilustração - uma das suas admiráveis ilustrações. Apareceu-me hoje aqui, mostrei-Ihe $O$ Cavalo, ficou radiante, e prometeu tudo. [...] Temos assim resolvido o $n^{\circ} 2$. Logo que possa, veja se o impressor começa, para sair em Abril. 
Veja se pode mandar ao Almada Negreiros algumas edições suas [...]. É, indiscutivelmente, o nosso maior. Ficou cheio de curiosidade por Você... (SERPA, 14 mar. 1950, grifos do original)

Fica acordado que os exemplares seriam enviados em caixas separadas, para que a alfândega portuguesa não cobrasse taxas de importação. As vendas esgotam-se rapidamente em Portugal, o que nos leva a crer que a revista teve ampla repercussão. Dias depois, Serpa informa que o décimo pacote parece ter sido extraviado e o oitavo fora violado. "Oxalá seja assim [todos se encontrem bem de saúde], e Você possa entregar-se aos trabalhos da sua oficina gráfica. [...] Já começaram os trabalhos do $\mathrm{n}^{\circ} 2$ ? Conseguiremos tê-lo pronto em Maio? Seria ótimo, para, com o $\mathrm{n}^{\circ} 3$, termos a regularidade..." (SERPA, 12 abr. 1950). Não havendo retorno do poeta sobre seus pedidos, Serpa desabafa:

Com a maior franqueza, avise-me, quando se cansar e quiser terminar. Eu bem calculo quantas estopadas Você tem com o Bicho... Não é justo que eu esteja aqui sem fazer nada, e Você aí com todo o trabalho. Acho melhor, no caso de continuarmos, não se datarem os números, dando-se-Ihes apenas números de ordem. Sairia, assim, apenas quando Você pudesse estar com isso... (SERPA, 21 maio 1950, grifos nossos)

Naquele mês de maio, durante suas férias, João Cabral submete-se a mais um tratamento de saúde. Apesar disso, a editora continua a publicar outros livros: em agosto, Cabral lançaria o seu Cão sem plumas, que Serpa acusa receber. Não há registros que indiquem a razão pela qual Cabral diminui o empenho na edição da revista, já que continua a publicar ativamente. Apesar disso, há mudanças na motivação de política de Cabral, que comunica ter solicitado a mudança de posto de trabalho para a Inglaterra. Serpa passa a ser o contato português para distribuir os próximos livros do amigo, mas a revista não é mais citada.

Em novembro, Alberto de Serpa desculpa-se por não ter escrito ainda para Londres. Lamentoso, pede ao amigo: "Vamos a ver se $O$ Cavalo aparece novamente. Eu queria muito, pois atirei-me para o seu lombo cheio de entusiasmo" (SERPA, 12 nov. 1950).

Estou há muito tempo sem notícias suas. [...] 
Toda a gente me pergunta pelo Cavalo. E eu dou-o, umas vezes, por afundado em mares tumultuosos, outras, fugido para as nuvens, deste mundo sem Poesia, horrorizado. Mas a verdade é que me custa muito vê-lo parado. Não poderá o João lançar um novo número de despedida? Vejo a impossibilidade de o mantermos, assim distantes como estamos: próximos, sei que o entusiasmo de um contagiaria o outro, e o Cavalo não tropeçaria. Assim, parece-me melhor, realmente, darmos a tarefa por finda. Chegou a enviar o $n^{\circ} 1$ para o Brasil? Tenho pena que não saiam os poemas do Pessoa. Veja, Amigo, se ainda tem coragem para lançar esse número 2. Talvez surgissem, depois, forças para continuarmos... Peço notícias urgentes sobre o caso. (SERPA, 28 maio 1951)

Efetivamente, as cartas trocadas aconteceram entre 19 de junho de 1949 a 21 de maio de 1950. Ao longo de um ano, portanto, os poetas criaram uma cujo projeto ficou aparentemente comprometido pela saúde de João Cabral e sua transferência. Com a ilegalidade do Partido Comunista em 1952, João Cabral de Melo Neto foi acusado de criar uma célula comunista no Itamaraty, ${ }^{3}$ colocando em disponibilidade o cargo do diplomata. Em março daquele ano, foi forçado a retornar ao Brasil sob a acusação de comunista. A acusação foi feita "devido à troca de correspondência com pessoas consideradas comunistas" e que "o Itamaraty teria descoberto o grupo pela violação de correspondência particular" (GALVE, 2016, p. 257).

Os pedidos de recursos ao mandato foram negados sucessivas vezes, impelindo Cabral a desenvolver outras habilidades da escrita, como a de tradutor e a de redator. Em 1953, mais um título é publicado: O marinheiro e a noiva, de Joel Silveira - este foi o último lançamento da editora Inconsútil. Sem possuir características físicas semelhantes aos impressos em Barcelona, é composto no Brasil (sem cidade identificada até o momento) durante o período em que João Cabral teve seu cargo público cassado, acusado por desenvolver atividades subversivas. Após retomar o seu cargo e dar continuidade à carreira diplomática, a editora $\mathrm{O}$ Livro Inconsútil foi oficialmente abandonada, assim como a revista $O$ Cavalo de Todas as Cores.

\footnotetext{
${ }^{3}$ Além de Melo Neto, foram acusados os diplomatas Antônio Houaiss, Amaury Banhos Porto de Oliveira, Jatyr de Almeida Rodrigues e Paulo Cotrim Rodrigues Pereira.
} 
O contato com Alberto de Serpa passa a ser espaçado, e é retomado ao enviar Duas águas àquele que continuou a ser seu leitor, ou como Serpa mesmo se definia, "seu amigo e admirador", mas as trocas de informações não seriam mais intensas. Em 1956, desde Andaluzia, o diplomata escreve a Alberto de Serpa agradecendo a crítica sobre seu novo livro e as informações para pesquisa sobre o lado português do Arquivo das Índias. Esclarece Cabral ao amigo que teve de vender a tipografia por ter estado ano e meio fora do Ministério, e diz: "melhor vendê-la do que vender-se". ${ }^{4} \mathrm{~A}$ revista não seria mais mencionada e a correspondência seria finalizada em 1966.

Alberto de Serpa participaria de outras revistas literárias portuguesas e faleceria na mesma década que João Cabral. Passado tantos anos, no entanto, é possível conjecturar a razão pela qual O Cavalo de Todas as Cores foi abandonado: o risco de censura e perseguição. João Cabral de Melo Neto não retomaria as Artes Gráficas, negaria sua experiência de $O$ Livro Inconsútil e passaria a afirmar ser um péssimo correspondente, pois detestava cartas. A Revista de Cultura Brasileña, publicação patrocinada pela Embaixada do Brasil, em Madrid, a partir de 1962, apresentaria literatura brasileira a espanhóis e vice-versa, e Cabral mediaria tradutores e poetas, mas apenas dentro do circuito oficial admitido pelo Itamaraty: não apoiaria mais diretamente perseguidos políticos.

Ao longo de sua vida pública posterior, Cabral justificou a compra da prensa manual e das famílias de tipos metálicos devido a uma recomendação médica para praticar exercício físico - e complementava que optara pela prensa já que não podia mais jogar futebol. A partir disso, passava a falar sobre os amigos catalães e desviava a atenção para o assunto. Este discurso, somado às obras posteriores do autor, direcionou a atenção da crítica para a linguagem literária, reforçou o paradigma do impresso no qual se assentam as Letras e, consequentemente, ajudou a limitar o diálogo que poderia existir entre as Artes Gráficas, a História e a Literatura. Poemas engajados, impressos literalmente pelas suas próprias mãos, ficariam no passado, dando espaço a interpretações restritas à rica linguagem de sua obra. O Cavalo de Todas as Cores, a revista que se propunha a ser trimestral, mas que teve um número só, seria apenas uma linha a mais na lista de suas obras organizadas - ou uma mera curiosidade bibliófila.

\footnotetext{
${ }^{4}$ Reconstrução de resumo indicado pela Biblioteca Municipal do Porto.
} 


\section{Referências}

BIBLIOTECA MUNICIPAL DO PORTO. Disponível em: <http://bibliotecas.cm-porto.pt/ ipac20/ipac.jsp?session=P5051545Q8G84.63380\&profile=bmp\&source $=\sim$ !horizon \& view=subscriptionsummary\&uri=full=3100024 !161703 $! 523 \&$ ri=1\&aspect $=$ subta b11\&menu=search\&ipp=20\&spp=20\&staffonly=\&term=alberto+de+serpa\&index $=$ GW\&uindex>. Acesso em 5 set. 2017.

BROSSA, Joan et all. Joan Brossa desde Barcelona ao Novo Mundo, Institut Ramon Llull/ Fundació Joan Brossa, Santiago do Chile/Barcelona, 2005.

CABRAL, Inez; MELO NETO, João Cabral de. A literatura como turismo. Rio de Janeiro: Alfaguara, 2016.

CADERNOS de Literatura Brasileira. João Cabral de Melo Neto, São Paulo, Instituto Moreira Salles, n. 1, mar. de 1996.

CARVALHO, Ricardo Souza de. Cavalo de todas as cores: Uma revista editada por João Cabral de Melo Neto. Revista USP, São Paulo, n.73, p. 112-116, mar./maio, 2007.

COLÓQUIO LETRAS. Paisagem Tipográfica: Homenagem a João Cabral de Melo Neto (1920-1999), Fundação Calouste Gulbenkian, Lisboa, n. 157/158, jul./dez., 2000.

GALVE, Fernanda. O navegar do poeta João Cabral no oceano das palavras proibidas (1952-64). VERINOTIO: Revista on-line de Filosofia e Ciências Humanas, n. 21, ano XI, abr., 2016. Disponível em: <http://www.verinotio.org>. Acesso em: 3 out. 2016.

MELO NETO, João Cabral de. Correspondência de Cabral com Bandeira e Drummond. Org. apres. Notas de Flora Süssekind. Rio de Janeiro: Nova Fronteira, Fundação Casa de Rui Barbosa, 2001.

MELO NETO, João Cabral de; SERPA, Alberto de (orgs.). O Cavalo de Todas as Cores. Versão online disponível em: <http://web.bg.uc.pt/wrapper.asp>. Acesso em 3 março 2015.

MORAES, Vinicius de. Querido poeta: correspondência de Vinicius de Moraes (seleção e organização Ruy Castro). São Paulo: Companhia das Letras, 2003.

SERPA, Alberto de. Correspondência manuscrita e datiloscrita com João Cabral de Melo Neto. Arquivos Pessoais de Escritores Brasileiros, pesquisa local. Fundação Rui Barbosa, Rio de Janeiro. (acervo não publicado). 